\title{
Moral Realism, Skepticism and Anti-realism: a Critical Analysis of the Criteria for Moral Realism
}

Deborah C. Smith

Kent State University

Disputatio No. 8

November 2001

DOI: $10.2478 /$ disp-2001-0005

ISSN: 0873-626X 


\title{
MORAL REALISM, SKEPTICISM AND ANTI-REALISM: A CRITICAL ANALYSIS OF THE CRITERIA FOR MORAL REALISM ${ }^{1}$
}

\author{
Deborah C. Smith \\ Kent State University
}

Despite the fact that realism has long been the dominant outlook in science, ethical realism has been thought to be especially problematic. Even the most steadfast realists in other fields have questioned the existence of moral truths. It seems that the would be moral realist has his work cut out for him. The first step necessary for any defense of moral realism will be the identification of the realist territory in moral disputes. To this end, Geoffrey SayreMcCord ${ }^{2}$ has offered criteria for "mapping off" the territory of the realist in any debate concerning realism.

The map I offer is, I believe, one that works not just for the moral realism debate, but also for all other debates concerning realism. Moved from realist debate to realist debate, the same map will serve to demarcate in each the issues that separate realists from anti-realists. Unlike most maps, which elaborately detail one area but are useless in the next, this map serves as a guide to realism wherever it occurs. ${ }^{3}$

If these criteria are successful, this should be of enormous philosophical help. With such a map in hand, identifying the moral realist should be relatively easy; any moral theory that falls within the territory marked off by the map is a realist moral theory. If the criteria are not successful, we may gain some insight into the nature of moral realism through examining the reasons for their failure.

This paper will be a critique of Sayre-McCord's criteria for identifying realism in any of its forms, and specifically its application in identifying the

\footnotetext{
1 This paper has benefited enormously from discussion with William Talbott and especially Elizabeth Oljar. A version of the paper was presented at the Pacific Division Meeting of the APA, 1995.

${ }^{2}$ Sayre-McCord, Essays on Moral Realism [hereafter EMR] (Ithaca: Cornell University Press, 1988).

${ }^{3}$ EMR, p. 5.
} 
ethical realist. In the first section, I will outline Sayre-McCord's criteria and their relevance in the moral dispute. In the second section, I will raise some objections against the criteria and conclude that they are not sufficient. I will also suggest an amendment to the criteria that should serve to make them sufficient for identifying realism as non-skepticism with regards to a certain disputed set of claims. Discussion of this amendment will illuminate the fact that moral realism can and should be formulated independently of the more metaphysical debate between realists and anti-realists concerning the correct theory of truth for natural language.

I.

Sayre-McCord offers two criteria that he believes a view must be committed to in order to count as a version of realism:

[1] The claims in question, when literally construed, are literally true or false.

[2] Some of the claims in question are literally true.

The first of these criteria requires that the view hold that the claims in question [e.g. moral claims] have cognitive content. The claims, when literally construed, must be construed as propositions having a determinate truth value. Thus, any form of non-cognitivism regarding the claims in question will express anti-realism. Such non-cognitivism with regard to moral statements is held by the emotivists ${ }^{4}$ and the prescriptivists. ${ }^{5}$ Both hold that ethical statements do not purport to refer to or describe facts in the world. Emotivists claim, rather, that ethical statements express approval or disapproval; prescriptivists claim that ethical statements express recommendations or prescriptions. Both views express moral anti-realism rather than realism.

The second criterion amounts to a denial of what is often called an "error theory." An error theory is one which, while agreeing that the claims in question have a truth value, holds that the truth value of all claims in question is, in fact, false. In "The Subjectivity of Values," J.L. Mackie clearly expresses such an error theory with regard to ethics. Mackie claims that ethical statements do purport to refer to objective moral values and principles. However, he argues that there are no such objective moral values or principles; all moral statements are, in fact, false. Mackie's view suggests that cognitivism with regards to moral claims is not sufficient for moral realism; one must also embrace a "success" theory, by acknowledging that some of the claims are

\footnotetext{
${ }^{4}$ See C.L. Stevenson, Ethics and Language (New Haven: Yale,1944).

${ }^{5}$ See R.M. Hare, The Language of Morals (New York: Oxford University Press, 1952).

${ }^{6}$ Mackie, Ethics: Inventing Right and Wrong (London: Penguin Books, 1977).
} 
literally true. It would now appear that anyone who advances a moral theory that acknowledges that there are literally true ${ }^{7}$ moral claims is a moral realist.

Sayre-McCord hopes that these two criteria will serve not just for the debate concerning moral realism, but will capture the nature of realism wherever it is found. For this reason, Sayre-McCord believes that it is a virtue of his account of realism that it makes no mention of objectivity, transcendence, independence from the mental, or bivalence. Sayre-McCord reasons:

Independence from the mental may be a plausible requirement for realism when we're talking about macrophysical objects but not when it comes to realism in psychology (psychological facts won't be independent of the mental); bivalence might go hand in hand with realism in mathematics, but realism in other areas seems perfectly compatible with acknowledging that some of our predicates are vague and have indeterminate extensions; and existence may be crucial to realism about scientific entities (since claims concerning such entities are true only if the entities exist) but not to realism about scientific laws (that make no existence claims). ${ }^{8}$

The idea seems to be that, if we require objectivity, bivalence, etc., for realism in general, we will rule out even the possibility of having a realistic view regarding certain sets of claims about which we might want, at least prima facie, to be realists. Sayre-McCord holds, and I think rightly so, that a set of criteria for realism that denies ipso facto the possibility of being realistic about, for example, mental states, should be somewhat suspect.

II.

Despite the surface plausibility of the view sketched above, there should be some immediate objections. A second look at Mackie will reveal a need to add a minor clarification to Sayre-McCord's second criterion for realism in order to capture more adequately moral realist claims. Claims about the nature or proper interpretation of ethical statements surely fall into the set of claims in question for determining whether a given view expresses moral realism. Such claims about the nature of ethical statements are second order or meta-ethical claims. These second order claims are relevant to how we should 'literally construe' first order ethical claims. For example, whether a view expresses cognitivism or non-cognitivism with regard to first order moral claims will be reflected in the second order claims accepted by the view. ${ }^{9}$

\footnotetext{
${ }^{7}$ More will be said below (Sec. III) about how we are to understand 'literal construal' and 'literal truth' of moral claims.

${ }^{8}$ EMR, p. 6.

${ }^{9}$ To be sure, even non-cognitivists will accept that second order claims have determinant truth value, and that some are literally true. For example, emotivists hold that the
} 
Thus, second order claims are crucial in determining whether or not a view meets our first criterion for moral realism. If Sayre-McCord's criteria are sufficient for identifying the moral realist, and since they fail to distinguish between first and second order claims, it would seem that any moral theory that asserted the truth of a second order proposition or set of propositions expressing a cognitivist interpretation for first order ethical claims would be properly identified as a version of moral realism. Such a theory would satisfy the second criterion by accepting that at least one of the claims in question is literally true, and would satisfy the first criterion in that the second order claim asserted as true expresses a cognitivist interpretation of first order moral claims. However, if this is the case, it appears that the criteria should identify Mackie (or any error theorist for that matter) as a moral realist. After all, Mackie not only agrees that the proposition 'Ethical claims and judgments purport to refer to objective moral values' has a truth value, but he also believes that this proposition is literally true (thus fulfilling our second "success" criterion). It is his very acceptance of this proposition that makes him a cognitivist with regard to first order ethical claims (thus satisfying our first criterion for realism). It would seem that Sayre-McCord's criteria should identify Mackie as a moral realist. Yet, as we have seen, Mackie believes that the proposition 'There are objective moral values' is, in fact, false. It is Mackie's belief that there are no objective moral values that figures most prominently in our intuition that he should be regarded as a moral anti-realist.

One strategy for amending the criteria so that they might correctly classify Mackie and other error theorists as moral anti-realists would be to restrict the scope of our criterion [2] to cover only first order claims. After all, the proposition that Mackie accepts as true that leads to the tentative identification of Mackie as a moral realist is a second order claim. Most first order ethical claims such as, 'Murder is wrong', 'One should keep his or her promises', when interpreted as expressing objective moral values, will come out false on Mackie's view. It is for this reason that Mackie's view expresses an error theory with respect to ethics. Unfortunately, there do seem to be some first order moral claims that even an error theorist like Mackie could assert. Consider the following: 'For every right there is a corresponding duty to respect that right. ${ }^{10}$ This is plausibly a first order moral claim. However, an error theorist can perfectly well assert such a sentence; it is just that on his

proposition 'Ethical statements, when literally construed, express approval and do not purport to describe facts about the world' is true. However, with the acceptance of the truth of this second order claim, emotivists violate our first criterion for moral realism, as none of the first order moral claims will have a truth value.

${ }^{10}$ Although this sentence reflects a deontological construal of moral claims, there are, I believe, analogous sentences that could be accepted by an error theorist that reflect consequentialist contruals of moral claims. 
view, there are no rights, and hence no corresponding duties. Thus, even if we restrict the scope of criterion [2] to first order moral claims, the criteria can still be seen to incorrectly identify Mackie and other error theorists as moral realists.

The misidentification of Mackie as a moral realist even given the restriction on criterion [2] reveals what I believe to be a deeper problem with SayreMcCord's criteria for realism. It would seem that the criteria do not capture one of our basic intuitions about realism, the intuition that a realist view carries certain ontological commitments. Indeed, it does not appear sufficient for realism that just any of the claims in question is true; there are particular claims of interest to the realist that must be true. Certain existence claims, for example, are of special importance to the realist, for one is a realist about some $X$. To illustrate this point, suppose I am claiming to be a realist about unicorns. I agree that claims about unicorns have cognitive content, and so meet the first criterion for realism. Further, I believe that some of these claims are literally true. For example, I hold that the statement 'If anything is a unicorn, it has a single horn' is true. It would appear that I satisfy the second criterion, however minimally. Yet, in what sense am I a realist about unicorns if I believe, as I do, that the proposition 'there are unicorns' is literally false? If the intuition in this case is that, if I don't accept the proposition 'there are unicorns', I am in no way a realist about unicorns, it would appear that SayreMcCord's criteria are not sufficient for identifying realism. If I am to be a realist about unicorns, it would seem that I must hold that there are some true claims about unicorns that have existential import. Similarly, it is Mackie's denial that there are objective moral values that seems to rule out the possibility that his view expresses moral realism. Indeed, this intuition is shared by Sayre-McCord who, contrary to what a rigid adherence to his criteria for realism would suggest, identifies Mackie as a moral anti-realist. The fact that a straightforward application of the criteria yields results which are inconsistent with Sayre-McCord's own views about who is a moral realist gives us compelling reasons for thinking that our second criterion for moral realism is not stringent enough and needs to be amended.

Is there a way to amend Sayre-McCord's criteria so that they capture this intuition sufficiently while preserving their relevance to other debates concerning realism? We might try to amend the second criterion for realism in such a way that it explicitly captures our intuition that a realist outlook carries with it existential import. We might, for example, claim that in order to be a realist with regard to $X$-claims one must meet, in addition to the cognitivism criterion [1], the following:

[2*] Some of the claims are literally true and among these true claims is one of the form 'There are Xs.' 
When 'objective moral values' is plugged in for the value of ' $X,{ }^{11}$ Mackie will fail to satisfy this new criterion and will be correctly picked out as a moral antirealist. This strategy has the advantage that it does not depend on a first order/second order distinction and limiting the scope of realism to first order claims. Yet, such an amendment to our second criterion for realism, seems in danger of bringing in concepts that will prima facie rule out the possibility of a realistic position in certain debates. Sayre-McCord might now object that with $\left[2^{*}\right]$ we are making explicit reference to existence, thus ruling out the possibility of realism with regard to scientific laws. However, this worry does not seem well founded. While realists about scientific laws in some sense make no existence claims, they do make the claim relevant to fulfilling [2*]. 'There are scientific laws and principles' is true according to such a realist. ${ }^{12}$

Although $\left[2^{*}\right]$ goes a long way toward capturing our intuition about the ontological claim made by realist views in general, some will object that more is needed to capture our intuition about the ontological claim made by moral realism. Moral realism, they'll argue, is not merely the claim that there are true statements regarding the existence of moral principles or values when literally construed; it is the view that these statements are true in virtue of the mind independent existence of such principles or values in the objective world. Such objectors might claim that moral realism requires truth-theoretic realism. Yet, as amended, Sayre-McCord's criteria [1] and [2*] will be insufficient to distinguish realists from anti-realists in the semantic debate over the appropriate truth theory for the natural language. ${ }^{13}$ To see why this is so we must take a brief semantic digression.

For the semantic or truth-theoretic realist, truth is the result of some type of correspondence between our propositions and brute facts about the external world, facts that are largely independent of our use of language. The truth-theoretic anti-realist, on the other hand, denies that truth is the result of correspondence with language independent facts, often, but not always, by denying that there are such facts. For such anti-realists, truth involves some sort of verification, or idealized rational acceptability; sometimes claims are

\footnotetext{
${ }^{11}$ Whether or not this value for ' $\mathrm{X}$ ' correctly captures the literally construal of ethical claims is a matter for debate. It is, however, part of the literal construal of ethical claims adopted by Mackie, and therefore, the correct value for ' $X$ ' according to his theory.

${ }^{12}$ There may yet be difficulties in formulating a nomological realism rather than an entity realism with the above amended criteria. I will ignore these difficulties here as it should be clear to the reader that an ontological claim such as the one suggested in $\left[2^{\star}\right]$ is required for moral realism, even if incompatible with nomological realism.

${ }^{13}$ This debate is frequently put in terms not of semantic or truth-theoretic realism, but of metaphysical realism. Although I have couched my discussion in terms of the semantic reading of the debate, I believe that my analysis will apply mutatis mutandis to the metaphysical reading.
} 
said to be true in virtue of linguistic or conceptual convention. ${ }^{14}$ It would appear that our criteria [1] and [2*] will not be able to distinguish the truththeoretic realist from the anti-realist. Both will claim that when literally construed, claims about the nature of truth itself are literally true or false (satisfying [1]). Both will agree that some of these claims are literally true, including the claim 'there are literal truths' (satisfying [2*]). Their debate is not over whether there are true statements, both agree that there are; rather, it is over how such claims about truth are to be literally construed.

We might try framing the truth-theoretic debate such that there is some existence claim that the truth-theoretic realist accepts but that the truththeoretic anti-realist denies. For example, if the truth-theoretic realist can claim that 'There are language independent brute facts about the world', and the truth-theoretic anti-realist cannot, then $\left[2^{*}\right]$ will be able to distinguish between them. However, the truth-theoretic anti-realist can accept the claim 'There are language independent brute facts about the world.' It is just that, for the truth-theoretic anti-realist, these facts are not what make our true statements true. On the other hand, it is not enough for truth-theoretic realism that there be extra-linguistic facts; the facts must play a critical role in determining the truth value of our propositions. What distinguishes the truththeoretic realist from anti-realist is not the bare existence claim about language independent brute facts, but rather the role such facts play (if any) in determining the truth of our true propositions. It appears that the truththeoretic realist cannot literally be said to be a realist about anything; he simply favors a particular truth theory for our natural language. If this is indeed the case, our amended criteria for realism will fail to distinguish the realist from the anti-realist in the truth-theoretic debate. If the criteria fail to identify the truth-theoretic realist and truth-theoretic realism is required for moral realism, the criteria will also fail to identify the moral realist.

That Sayre-McCord's criteria cannot be extended to capture the truththeoretic debate over realism is not, I believe, a defect. Rather, it reveals what I believe to be a crucial insight: there are, in fact, (at least) two distinct debates whose opponents, for better or worse, have traditionally been called realists and anti-realists. Both the debate over the status (especially ontological commitments) of a particular set of disputed claims, and the debate over the correct truth theory for the natural language have been identified as debates between "realists" and "anti-realists." To make this distinction explicit, I will hereafter refer to the two positions in the debate concerning the appro-

\footnotetext{
${ }^{14} \mathrm{My}$ account of semantic realism and anti-realism is very similar to and largely derived from Hilary Putnam's account of externalist and internalist views as presented in Reason, Truth and History (Cambridge: Cambridge University Press, 1981). For a more recent and more thorough treatment of the semantic realism/anti-realism debate, see William Alston's, A Realist Conception of Truth (Ithaca: Cornell University Press, 1996)
} 
priate truth theory for the natural language as 'truth-theoretic realism' and 'anti-realism' respectively, and refer to the realist position in the debate concerning the status of a particular set of disputed questions as 'nonskepticism', the anti-realist position in the same debate as 'skepticism'. ${ }^{15}$ Sayre-McCord's criteria [1] and [2*] can now plausibly claim to give necessary and sufficient conditions for non-skepticism concerning a disputed set of entities or laws. The reason that Sayre-McCord's criteria are unable to distinguish the truth-theoretic realist from the anti-realist is, I believe, that either may hold a skeptical or non-skeptical position with respect to any set of claims, and a fortiori, to moral claims. ${ }^{16}$

Anyone who would still claim that truth-theoretic realism is required to be non-skeptical about anything will find this distinction highly implausible. Such a person would argue that if truth-theoretic realism is false, then all forms of non-skepticism are necessarily false. If the claim 'there are $X \mathbf{s}^{\prime}$ is not true in virtue of correspondence with the external world, then the Xs cannot be said to really exist. I find this line of argument to be overly dogmatic. Should truththeoretic anti-realism turn out to be correct, there will still be reason to distinguish between existence claims about, e.g., tables and chairs which are literally true, and existence claims about, e.g., unicorns or other fictional entities which are literally false. There will still be reason to question whether moral claims are more like claims about tables and chairs or more like claims about unicorns. It is this question that encompasses the debate concerning moral skepticism, regardless of truth-theoretic outlook. So long as we are dealing with a truth theory that allows for the distinction between literal and non-literal truth and falsity we can make the further distinction between skepticism and non-skepticism about moral claims.

To sum up, Sayre-McCord's criteria for realism as originally formulated are not sufficient for identifying the moral realist. The criteria fail to capture our basic intuition that realist claims have existential import. This failure has the result that application of the criteria yields results which are inconsistent

\footnotetext{
${ }^{15}$ It is important to note that my use of the terms 'skepticism' and 'non-skepticism' is distinct from most epistemological uses of the terms. In using the term 'moral skepticism' in place of 'moral anti-realism' I am following the usage of Mackie in Ethics: Inventing Right and Wrong, and Panayot Butchvarov in his Skepticism in Ethics (Bloomington: Indiana University Press, 1989). A moral non-cognitivist is a skeptic with respect to the cognitive content of moral claims. An error theorist such as Mackie is a skeptic with respect to the truth value of any moral claims that have existential import, such as the claim 'there are objective moral values'. If either counts as a skeptic in the epistemological sense, that is, if either claims that we cannot know any moral claims to be true, it is only trivially--he simply denies that there are any moral truths to know.

${ }^{16}$ It is worth noting that Sayre-McCord would likely agree with this claim. See his footnote 13 on p. 6 .
} 
with Sayre-McCord's own views about who is and who is not a moral realist. We can amend the criteria (replacing [2] with [2*]) by adding the requirement that among the literally true claims accepted by the theory there be one of the form 'There are Xs'. Application of the criteria so amended yields more consistent results. Even so, the amended criteria are insufficient for distinguishing between truth-theoretic realism and anti-realism. I hope that I have made the case that this is by no means a flaw in the criteria, but rather results from the fact that there are two distinct debates that have been traditionally called debates concerning realism: the debate between truth-theoretic realists and anti-realists, and the debate concerning skepticism with regard to a particular set of claims. Once this distinction is noted, our amended formulation of Sayre-McCord's criteria can claim to give necessary and sufficient conditions for being non-skeptical with respect to a disputed set of claims.

III.

In this paper I have shown that Sayre-McCord's criteria for moral realism (non-skepticism) are not sufficient as stated. I have suggested an amendment that is sufficient for capturing our intuitions that realism (non-skepticism) in general entails certain ontological commitments. Although the suggested amendment cannot distinguish truth-theoretic realism from anti-realism, this is a virtue of Sayre-McCord's account, as the truth-theoretic debate is independent of the debate focused on in this essay. Besides arguing that the truth-theoretic debate concerning realism is independent of debates concerning moral non-skepticism, I have said nothing concerning how moral claims, in particular, should be literally construed. While the appropriate notion of the 'literal truth' of ethical claims will depend on the truth theory adopted for the whole natural language, the same is true of the literal truth of other non-moral claims, and thus not unique to moral non-skepticism. It would be presumptuous to require any particular truth theory for our analysis of moral claims from the outset, as there is still great debate as to the correct analysis of truth in natural language. ${ }^{17}$ Rather than put the debate concerning

\footnotetext{
${ }^{17}$ Sayre-McCord himself indicates that he favors what I have called a realist theory of truth as part of the literal construal of moral claims. "No simple subjectivist or intersubjectivist interpretation of the claim that ' $x$ is wrong' does justice to the meaning of moral language (although more sophisticated versions might). And unless a proposal can be defended as offering the right truth-conditions for moral claims literally construed, it can form no part of a defense of moral realism. Realism requires that the moral claims, literally construed, be literally true. So when faced with an implausible account of the truth conditions for moral claims, the charitable interpretation of the proposal is that it rests on the view that moral claims, as literally construed, should be jettisoned in favor of some new language. Such a proposal, if it is to be taken seriously, will have to find
} 
moral skepticism on hold pending an outcome in the truth-theoretic debate, I recommend that moral skeptics and non-skeptics concentrate on aspects of the literal construal of moral claims that are unique to such claims. For example, must moral claims be construed as having internal motivational force to yield moral non-skepticism? Must they be construed as claims about natural properties? About non-natural properties? The fact that such questions remain open should be further evidence that moral skeptics and nonskeptics have much to discuss that is completely independent of the debate concerning truth-theoretic realism.

Deborah C. Smith

Kent State Univesity

Dept. of Philosophy

P.O. Box 5190

Kent, $\mathrm{OH}$ 44242-0001, USA

dcsmith1@kent.edu

its motivation in a prior acceptance of [skepticism] for moral claims as literally construed" (p. 22). This passage suggests that an anti-realist theory of truth for moral claims is implausible. However, the implausibility seems to only arise when we assume that we have an adequate realist theory of truth for other types of claims, especially claims about tables and other middle sized material objects. That is, subjectivist and intersubjectivist truth theories for ethical claims are implausible given that the realist has already won the larger truth-theoretic debate for natural language. With this I have no quarrel. However, it seems hasty to require a realist account of truth for moral claims in advance of an outcome in the truth-theoretic debate in general. 